\title{
ATRIBUTOS FísICOS DO SOLO EM ÁREAS DE SERINGUEIRA E PASTAGEM EM MONOCULTIVO CONTRASTADO AO SISTEMA SILVIPASTORIL
}

\author{
Gustavo Pereira Valani ${ }^{1}$ \\ Gleison Oliosi ${ }^{2}$ \\ Ivoney Gontijo ${ }^{3}$ \\ Fábio Luiz Partelli ${ }^{4}$
}

Resumo: O sistema silvipastoril possui potencial de reduzir a erosão, reduzir a necessidade de fertilizantes minerais e de melhorar as propriedades dos solos. O trabalho teve como objetivo avaliar os atributos físicos do solo em diferentes tipos de manejo do solo no norte do Espírito Santo. O experimento foi realizado em Jaguaré - ES. Avaliou-se a densidade do solo, densidade de partículas, volume total de poros, macro e microporosidade e resistência do solo a penetração nas profundidades de 0 a 10 e de 10 a $20 \mathrm{~cm}$ em áreas de seringueira em monocultivo, pastagem em monocultivo, sistema silvipastoril (de seringueira com pastagem) e fragmento de mata atlântica. Os atributos físicos do solo variaram em função das profundidades e das áreas avaliadas. O sistema silvipastoril apresentou menor densidade do solo, menor resistência à penetração e maior microporosidade que o cultivo de pastagem em monocultivo, indicando um efeito positivo no consórcio de pastagem e seringueira.

Palavras-chave: Física do solo; Hevea brasiliensis; Brachiaria brizantha; Sistema silvipastoril.

\footnotetext{
1 Agronomia/Universidade Federal do Espírito Santo, Brasil. E-mail: gustavo.valani@hotmail.com.

2 Agronomia/Universidade Federal do Espírito Santo, Brasil. E-mail: gleison.oliosi@hotmail.com.

${ }^{3}$ Agronomia/Universidade Federal do Espírito Santo, Brasil. E-mail: ivoneygontijo@yahoo.com.br.

${ }^{4}$ Agronomia/Universidade Federal do Espírito Santo, Brasil. E-mail: partelli@yahoo.com.br.
} 